\title{
How does market orientation affect product innovation in China's manufacturing industry: The contingent value of dynamic capabilities
}

\author{
Jing liu ${ }^{1}$ (Correspondence author) \\ Academic Department of Management and Economics \\ Dalian University of Technology, Dalian, China \\ Email:Jingliu1221@126.com
}

\author{
Jingqin Su \\ Academic Department of Management and Economics \\ Dalian University of Technology, Dalian, China, \\ Email: su_jingqin@126.com
}

\begin{abstract}
We conceptualize and empirically test a mode that links different types of market orientation and product innovation, moderating by dynamic capabilities. Survey responses from China's manufacturing industry firms indicate that niche market orientation is more strongly positively related with product innovation than is mass market orientation. Meanwhile firms with high levels of dynamic capabilities better effects two types of market orientation and product innovation. The results have significant implications for firm strategies to facilitate product innovations and achieve competitive advantages.
\end{abstract}

Keywords- Market orientation, Dynamic capabilities, Product innovation ' Manufacturing industry

\section{INTRODUCTION}

What determines product innovation? To answer this question, most existing literature has focused on the research in strategic orientation, in particular, various studies have provided empirical support for the positive link between market orientation and firm performance. suggest that market-oriented behavior yields superior innovation and greater new product success. Grewal and Tansuhaj (2001), extending this view, conclude that businesses with a strong market orientation are best situated for new product success, even under an economic crisis. With such strong conceptual and empirical support, market orientation has become a pivotal construct that affects a firm's product innovation.

In this study, we focus on several issues. Specifically, we divided market orientation into mass market orientation and niche market orientation, and then ask: (1) How do mass market orientation and niche market orientation influence product innovation in the Chinese manufacturing industry setting? (2) How do dynamic capabilities, a key firm capability for organizing innovation-related resources, moderate the relationship between the two types of market orientation and product innovation? To answer these questions, we propose an integrative model arguing that both $\mathrm{m}$ mass market orientation and niche market orientation affect a firm's innovativeness, which refers to the propensity of a firm to innovate, and we also addresses how dynamic capabilities moderates the relationship between market orientation and product innovation. Literature reviews

\section{A. Mass market orientation and niche market orientation}

Mass market orientation and niche market orientation generally differ in observable ways. First, they differ in customers' needs, in the case of mass market orientation, the company puts its efforts into discovering and understanding the current and mass needs of its customers. In contrast, the focus of niche market orientation is on a need for special treatment, which has customer goodwill. Second, research and development intensity under mass orientation and niche orientation is different, in the case of niche market orientation, the research and development intensity is high, mass market orientation, on the other hand, is relatively low compared with niche market orientation. Using the case of Sri Lankari valued-added tea producers, Ariyawardana (2003) have developed measurement scales to prove differences between mass market orientation and niche market orientation. Third, they can be characterized by differences in organizations. A company with mass market orientation can be characterized as being centrally led and bureaucratic which may lead to inflexibility. In contrast, niche market orientation organizations can be characterized as being decentralized, with several strategic business units if the company is large. Meanwhile, it can be characterized as being concentrated on one part of the market if the company is small.

Recognizing these differences, we argue that mass market orientation and niche market orientation have intrinsically different efficiencies for supporting product innovation. First, niche market orientation is an effective strategy for countering price competition in a mature industry, which may lead to new product success with a thorough understanding of the targeted consumers. Second, the key idea about product innovation based on niche market orientation is specialization and he provides the following ways in which to specialize: customer-size specialization, product or product-line specialization, product-feature specialization and quality/price specialization. Third, niche market orientation is more equipped to deal with the existing and rapid changing mini markets, which has recently become a trend as a result of severe competition in mature markets. According to Rapp and Collin (1990), the return on investment in product innovation from mass markets averaged 11 percent. By contrast, the return on investment in product innovation from niche markets was 27 percent. According to Peters 
(1990), the backbone of German economic success is the small and mid-sized companies, almost all of which are niche marketers.

In keeping with previous research, we expect that organizations with niche market orientation ends up knowing the target customer so that he meets their needs better than firms with mass market orientation. Thus, we argue that niche market orientation is superior to mass market orientation in the power to support product innovation for Chinese firms. Therefore, we argue:

$H 1$ Chinese firms with niche market orientation will have a strong positive relationship with product innovation than will with mass market orientation.

\section{B. The moderating role of dynamic capabilities}

This argument is derived from the dynamic capabilities perspective, which addresses how firms can build competitive advantage in turbulent environments. Teece (1997) defined dynamic capabilities as a firm's behavioral orientation constantly to integrate, reconfigure, renew and recreate its resources and capabilities and, most importantly, upgrade and reconstruct its core capabilities in response to the changing environment to attain and sustain competitive advantage. This definition illustrates two important aspects. First, according to Zhan and Chen (2010), firms with dynamic capabilities will innovate and renewing their competitive advantage adapt to dynamic environments, especially in emerging economy. Second, dynamic capabilities are the capabilities by which firms' resources are acquired and deployed in ways that match the firm's market environment that explains inter-firm performance variance over time. Therefore, firms with dynamic capabilities respond to dynamic operating environment by formulating their strategic orientation. Consequently, the dynamic capabilities perspective indicates that effective strategic orientation management is closely related to product innovation. Therefore, we examine the interactive nature of market orientation and organization for product innovation. Therefore, we argue:

H2 Dynamic capabilities will positively moderate the relationship between mass market orientation and product innovation.

H3 Dynamic capabilities will positively moderate the relationship between niche market orientation and product innovation.

Figure 1 schematically outlines our theoretical framework.

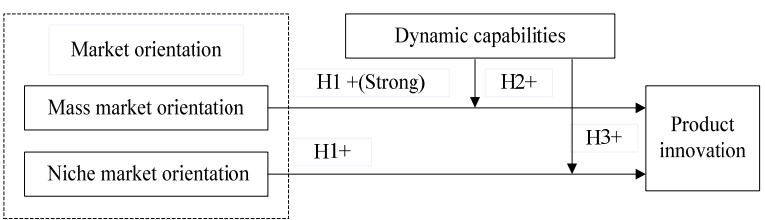

Figure 1. Conceptual model

\section{Methodology}

\section{A. Data collection}

To test our research hypotheses, we examined manufacturing firms located in five major cities (Beijing, Liaoning, Tianjin, Heilongjiang and Changchun) in mainland China. To collect the data, a questionnaire was developed and administered on-site to respondents by trained interviewers. A sample of 750 companies located in five cities were randomly selected from a company catalog published by CMP(China Machine Press) in 2010. The sample firm should meet the following three qualifications. First, it should be a manufacturing firm. Second, it should have existed for at least ten years, for we would inquire about the business performance in past three years in the questionnaire. Third, it should have autonomy in decision making of production, R\&D and marketing. These firms span diverse manufacturing industries, which increases the generalization of our findings.

\section{B. Measures}

Five-point Likert scales (from 1 - strongly disagree to 5 - strongly agree) were used and are shown in the appendix. Existing measures which have been validated in the contexts of developed economies were used or adapted to suit the purpose of this study. We modified some items according to operational conditions in China suggested in field interviews with managers.

We developed the measure of mass market orientation and niche market orientation on the basis of Greenley's (1995) work as no mature scales about mass market orientation and niche market orientation have been developed. The items emphasize a firm's proactivity and strategic orientation in expanding, controlling and managing market under dynamic environment because China has been experiencing extensive changes during its transition to a market economy and purified by our research. A four-item scale measured product innovation, with items drawn from empirical studies such as Alegre, Lapiedra and Chiva (2006). Dynamic capabilities were measured using scales derived from Sher and Lee (2004).

Finally, we measured firm size and firm age as control variables in our moderated regression model. Firm size was measured as the natural logarithm of the number of employees. Meanwhile, we measured firm age by the number of years a firm has been operating. We controlled for entry barrier because of its influence on product innovation performance. We measured it by asking respondents to indicate the degree to which "it is difficult to enter the markets far away from our home-base market when developing a new product.”(1 = “strongly disagree”, 7 = "strongly agree"). 


\section{RESULTS}

\section{A. Reliabilities and validities}

We present the basic descriptive statistics and correlations of the measures in Table 1 . To assess the internal consistency and reliability of the latent variables, we calculated the Cronbach's alpha for each construct. As Table 1 shows, the coefficient alphas of all constructs are above 0.60 , thus showing sufficient reliability for all the theoretical constructs. Alternatively, according to Bagozzi and Yi (1988), we computed the composite reliability (CR) scores to assess construct reliability. As Table 3 shows, all factors have CRs greater than 0.70 , indicating adequate reliability.

\begin{tabular}{lccccccc}
\multicolumn{7}{l}{ Table 1 Basic Descriptive Statistics of the Constructs } \\
\hline Construct & 1 & 2 & 3 & 4 & 5 & 6 & 7 \\
\hline 1. Firm size & 1.00 & & & & & & \\
2. Firm age & $.42^{* *}$ & 1.00 & & & & & \\
3. Entry barrier & $-.12^{*}$ & -11 & 1.00 & & & & \\
4. Mass market orientation & .05 & $.15^{*}$ & $-.20^{* *}$ & 1.00 & & & \\
5. Niche market orientation & .10 & -.03 & $.12^{*}$ & $.41^{*}$ & 1.00 & & \\
6. Dynamic capabilities & $.13^{*}$ & -.01 & $-.17^{* *}$ & .06 & $.32^{* *}$ & 1.00 & \\
7. Product innovation & .14 & .04 & $-.20^{* *}$ & .43 & $.16^{*}$ & .09 & 1.00 \\
Mean & 2.7 & 20.1 & 4.6 & 7.1 & 4.5 & 4.7 & 5.0 \\
Standard deviation & .87 & 1.97 & 1.64 & .98 & 1.52 & 1.47 & 1.64 \\
\hline${ }^{*} \mathrm{p}<0.05$ (two-tailed). & & & & & & & \\
${ }^{* *} \mathrm{p}<0.01$ & & & & & & &
\end{tabular}

To test the convergent and discriminant validity, we followed Anderson and Gerbing's (1988) procedures and used the CFA measurement model. According to Fornell and Larcker (1981), discriminant validity exists if the items share more common variance with their respective construct than any variance the construct shares with other constructs. According to Bagozzi and $\mathrm{Yi}$ (1988), the correlation between each pair of constructs should be less than the AVE square root for each individual construct. As Table 2 shows, all factor loadings on its corresponding construct are above 0.60 , and each average variance extracted (AVE) of latent construct is above the cut-off valued of 0.50, proving sufficient support for the latent constructs with the squared root of AVE to examine the discriminant validity between constructs. Comparing the correlation coefficients with the AVE square root in Table 2, no correlations are higher than the AVE square root for each construct, which indicates discriminant validity.

\begin{tabular}{|c|c|c|c|c|c|}
\hline Latent variables & Observed variables & $\alpha$ & Loading & $\mathrm{CR}$ & AVE \\
\hline \multirow{3}{*}{$\begin{array}{l}\text { Mass market orientation } \\
\text { (Narrere ta a.2004; } \\
\text { Greenley,1995; } \\
\text { Dalicic \& Leeuw, 1994) }\end{array}$} & 1. Engaging in the mass production of one product for large markets & \multirow{3}{*}{.795} & .715 & \multirow{3}{*}{.882} & \multirow{3}{*}{.715} \\
\hline & 2. Engaging in the mass distribution of one product for all markets & & .814 & & \\
\hline & $\begin{array}{l}\text { 3. Focusing on mass promotion of one product for all buyers } \\
\text { 4. Attemnting to treach huveres with one product with one marketing mix }\end{array}$ & & .802 & & \\
\hline \multirow{3}{*}{$\begin{array}{l}\text { Niche market orientation } \\
\text { (Narver et al,2004; } \\
\text { Dalgic \& Leeuw, 1994) }\end{array}$} & 1. Focusing on individuals, in a segment we focus on a socalled homogeneous group & \multirow{3}{*}{.638} & .710 & \multirow{3}{*}{.787} & \multirow{3}{*}{539} \\
\hline & 2. Searching for new opportunities for healthy profits in small markets & & .826 & & \\
\hline & 3.Creating new experience curves and shaping a strong corporate culture and vision & & .689 & & \\
\hline $\begin{array}{l}\text { Dynamic capabilities } \\
\text { (Eisenhard \& Martin.2000; }\end{array}$ & $\begin{array}{l}\text { 1. Enhanced customer relationships } \\
\text { 2. Enhanced canbilities of resource denlovn }\end{array}$ & \multirow{3}{*}{.839} & .816 & \multirow{3}{*}{.891} & \multirow{3}{*}{.684} \\
\hline $\begin{array}{l}\text { (Eisenhardt\& Martin,2000; } \\
\text { Tece, Pisano \& Shuen, } 1997\end{array}$ & $\begin{array}{l}\text { 2. Enhanced capabilitites of resource deployment } \\
\text { 3. Enhanced responsiveness }\end{array}$ & & 799 & & \\
\hline Sher \& Lee,2004) & 4. Enhanced integration in new product development & & 856 & & \\
\hline $\begin{array}{l}\text { Product innovation } \\
\text { (Atuahene-Gima \& Ka,2001; } \\
\text { Alegre, Lapiedra \& Chiva2006) }\end{array}$ & $\begin{array}{l}\text { 1. Superior to competing products for meting customers' needs } \\
\text { 2. Offering benefifts highly visible than previous products } \\
\text { 3. Having new aspects compared with previous producs }\end{array}$ & .711 & $\begin{array}{l}.768 \\
.799 \\
.866\end{array}$ & .812 & .535 \\
\hline
\end{tabular}

\section{B. Findings}

We used a hierarchical multiple regression analysis to examine the hypotheses. Table 3 presents the results of hierarchical multiple regressions used to examine the hypotheses with product innovation as a dependent variable.

First, we entered the control variables, firm size, firm age and entry barrier, into the equation, which was significant $(\mathrm{F}=4.056, \mathrm{p}<0.01)$. As Table 4 shows: (1) Firm size $(\beta=0.155, p<0.01)$ and firm age $(\beta=-0.087)$. This result indicates that the stronger the firm, the higher the possibility that the firm is innovative which is in line with the work of Camisón-Zornoza, Lapiedra-Alcamí, Segarra-Ciprés, and Boronat-Navarro (2004) who suggested there is a significant and positive correlation between organization size and innovation. (2) Entry barrier $(\beta=-0.11, p<0.01)$. This result indicates that the stronger the firm, the more difficult to enter the markets the lower the possibility that the firm is innovative, which is consistent with the perspective of Zhou, Yim and Tse's (2005).

Next, we entered the independent variables of mass market orientation and niche market orientation into the regression equation respectively. Consistent with our predictions in Hypothesis 1, the results show that both mass market orientation and niche market orientation positively affect product innovation (Table3). The coefficient of niche market orientation is 0.195 and is significant in Model 2, while the coefficient of mass market orientation is 0.145 and is significant in Model 3. These results suggest a positive relationship between the two types of market orientation and product innovation. To test which type of market orientation has a stronger impact on product innovation, we then tested the relative power of mass market orientation and niche market orientation on innovation by comparing the change in $R^{2}$ in Models 2, Model 3 and Modes 4.

$$
\begin{aligned}
& \Delta R_{\text {Model4-Model2 } 2}^{2}=R_{\text {Model4 }}^{2}-R_{\text {Model2 }}^{2}=0.015, \\
& \Delta R_{\text {Model4-Model3 }}^{2}=R_{\text {Model4 }}^{2}-R_{\text {Model3 }}^{2}=0.033
\end{aligned}
$$

Here $\Delta R^{2}$ Model4-Model2 represents the proportion of the variance of product innovation that mass market orientation can explain. $\Delta R_{\text {Model4-Model3 }}^{2}$ represents the proportion of the variance of product innovation that niche market orientation

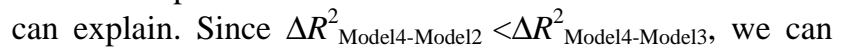
conclude that niche market orientation plays a more significant role than mass market orientation in promoting the firm's product innovation. The hierarchical F-values confirm that this $\Delta R^{2}$ differentce is statistically significant. The result indicates that niche market orientation has a stronger positive impact on product innovation than dose mass market orientation, in support of Hypothesis 1. A $t$-test of the equality of the two coefficients indicates that the coefficient of niche market orientation is significantly greater than that of mass market orientation for product innovation. Thus, Hypothesis 1 receives mixed support.

Finally, we entered the moderating factor dynamic capabilities and its interactions into the regression equation. 
From Model 5, we see that the coefficient of niche market orientation $X$ dynamic capabilities is significant positive ( $\beta=0.215, p<0.01)$, meanwhile, the coefficient of mass market orientation $X$ dynamic capabilities is also significant positive $(\beta=0.198, \quad p<0.01)$. Therefore, Hypothesis 3 is supported.

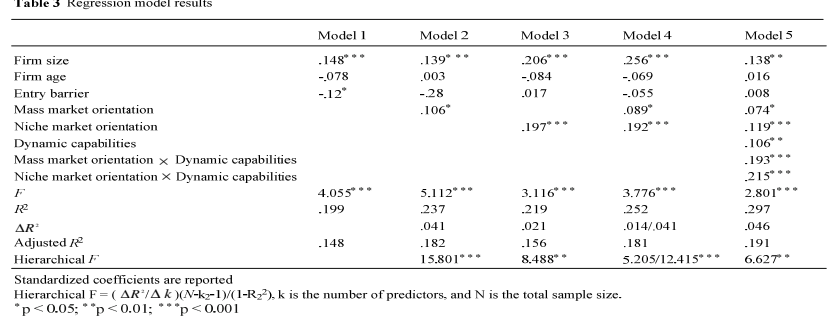

\section{CONCLUSIONS}

\section{A. Theoretical contributions}

This article provides several important implications to the product innovation area. First, this study examines the relationships between different types of market orientation and product innovation in the context of Chinese manufacturing industry which is among the first that directly examines the relative importance of mass market orientation and niche market orientation on product innovation, thereby filling a research gap about how market orientation affect product innovation. We find that both mass market orientation and niche market orientation have a positive impact on product innovation. These findings help solve the ongoing debate about the effect of market orientation on innovation as described at the beginning of this article.

Second, whereas extant studies of market orientation have focused mainly on the orientation-performance relationship and left the underlying process largely untapped. We explore the mediating role of dynamic capabilities which acts as a partial mediator between market orientations and product innovation. Our findings indicate that dynamic capabilities act as a partial mediator between market orientation and product innovation. Firms with high levels of dynamic capabilities show a better relation between both mass market orientation and niche market orientation and product innovation. This suggests that market orientation as firm strategy do not automatically lead to better performance.

Third, our study represents an initial effort to distinguish empirically between mass market orientation and niche market orientation and to assess their differential effects on product innovation performance. Both types of market orientations are beneficial to innovation performance, but niche market orientation has a greater impact on performance than does mass market orientation, possibly because the former provides improved benefits for target customers in potential profitable markets. These findings echo the call for more research to assess the innovation performance effects of different types of market orientations.

Fourth, this study adds to the innovation literature by testing a model with data from companies in an emerging economy. In an emerging economy, such as China, private and public enterprises have had to develop unique strategies to cope with the broad scope and rapidity of economic and political change in emerging economies. Our findings indicate that market orientation theories originate in developed economies appear applicable to emerging economies as well, given that the results support most of our hypothesized effects. Our study also extends research on emerging economies by showing how firms should strategize with capabilities in the turbulent environment.

\section{B. Managerial implicaitons}

This study provides several managerial implications for firms to facilitate product innovations. First, firms with market orientation are able to identify customers' latent needs and satisfy those needs by offering innovative products. However, adopting a market orientation alone hinders the potential and emerging markets. According to our results, firms should couple a market orientation with dynamic capabilities, which enables firms to excel in future competition for new product production.

Second, when a market becomes highly competitive, it is increasingly difficult for firms to differentiate themselves from their competitors. Our findings suggest that a focus on niche market is a feasible strategy. By targeting new and unserved segments, firms can develop new precuts that seize opportunities in emerging markets.

Finally, If the firm chooses mass market orientation, it should put much emphasis on expanding markets providing with one product for large markets and engaging in the mass distribution of one product for all markets. Meanwhile, for those firms adopting niche market orientation, the firm should focus more on individuals, searching for new opportunities for healthy profits in small markets. Thus, firms should choose the priority of market orientation strategy in extent of internal and external environment in order to maximum the potential benefits of strategic orientation.

\section{Limitations and further research}

As an initial effort to address a complicated phenomenon, this study is subject to several limitations. This study focuses mainly on the link between market orientation and product innovation. Additional research should expand our model by considering other important firm resources and capabilities, such as organizational learning and technology capability. Furthermore, dynamic capability is a multidimensional construct, so further research should identify different dynamic capabilities dimensions may moderate the market orientation-innovation linkage to understand how market orientation works.

Moreover, our empirical findings are based on data from China. Although China shares many characteristics with other emerging economies and emerging industries in developed economies in terms of consumer behavior, technology development and market environment, it also possesses some idiosyncrasies. Therefore, further research 
should corroborate our market orientation-innovation study in other developing and developed countries.

\section{REFERENCES}

[1] Grewal, R. and Patriya, T. (2001), "Building organizational capabilities for managing economic crisis: the role of market orientation and strategic orientation”, Journal of Marketing, Vol.65, pp.67-80.

[2] Ariyawardana, A. (2003), "Sources of competitive advantage and firm performance: the case of Sri Lankan value-added tea producers", Asia Pacific Journal of Management, Vol.20 No.1, pp.73-90.

[3] Rapp, S. and Collins, T. (1990), The Great Marketing Turnaround: The Age of the Individual and How to Profit, Prentice-Hall, Englewood-Cliffs, NJ.

[4] Peters, T. 1990. The German Economic Miracle Nobody Knows. Across the Board, April:16-23.

[5] Teece D.J. (2007), "Explicating dynamic capabilities: the nature and microfoundations of (sustainable) enterprise performance", Strategic Management Journal, Vol.28 No.13, pp.1319-1350.
[6] Greenley, G. E. (1994), “Market orientation and company performance: empirical evidence from UK companies", British Journal of Management, Vol.6 No.1, pp.1-13

[7] Slater, S.F. and Narver, J.C. (1994), "Dose competitive environment moderate the market orientation-performance relationship?”, Journal of Marketing, Vol.58 No.1, pp.46-55.

[8] Voss, G.B. and Voss, Z.G. (2000), "Strategic orientation and firm performance in an artistic environment", Journal of Marketing, Vol.64 No.1, pp.67-83.

[9] Alegre, J., Lapiedra, R. and Chiva, R. (2006), “A measurement scale for product innovation performance", European Journal of Innovation Management, Vol.9 No.4, pp. 333-346.

[10] Eisenhardt, K.M. and Tabrizi, B.N. (1995), "Accelerating Adaptive Processes: Product Innovation in the Global Computer Industry", Administrative Science Quarterly, Vol.40 No.1, pp.84-110.

[11] Bagozzi, R. P. and Yi, Y. (1988), "On the evaluation of structural equation models”, Academy of Marketing Science, Vol.16 No.1, pp.74-94.

[12] Zhou, K.Z., Kin, C.Y. and Tse, D.K. (2005), "The effects of strategic orientations on technology - and market-based breakthrough innovation”, Journal of Marketing, Vol.69 No.2, pp.42-60. 